\title{
Photophysical Properties of 2-Hydroxytryptanthrin Analog as a Near-Infrared Dye for Fluorescent Imaging
}

\author{
Jun Kawakami*, Chika Osanai and Shunji Ito \\ Graduate School of Science and Technology, Hirosaki University, 3 Bunkyo-cho, Hirosaki, Aomori 036-8561, Japan \\ * Corresponding author: Fax: 81-172-39-3541, e-mail: jun@hirosaki-u.ac.jp
}

2-Hydroxytryptanthrin analog (2-(2-hydroxy-12-oxoindolo[2,1-b]quinazolin-6(12H)ylidene)malononitrile, DCM-T2OH) was synthesized as a near-infrared (NIR) dye for fluorescent imaging. In high-polarity aprotic solvents (acetonitrile, $N, N$-dimethylformamide, and dimethyl sulfoxide), protic solvents (methanol and ethanol), and an aqueous solution containing $20 \%$ acetonitrile, both the absorption and fluorescence bands of DCM-T2OH were observed at the NIR region (650-900 $\mathrm{nm}$ ), which is referred to as the "optical window" of cells and tissues.

Key words: Near-infrared fluorescence, Fluorescent dye, 2-Hydroxytryptanthrin

\section{INTRODUCTION}

Fluorescent analysis reagents such as fluorescent chemosensors and fluorescent probes that are based on organic fluorescent dyes are simple and highly versatile and in particular, they have become indispensable as molecular tools for understanding biological phenomena in life sciences $[1,2]$. We have been exploring the photophysical properties of tryptanthrin derivatives as novel fluorescent dyes [3-10]. Tryptanthrin (T, Fig. 1a) is a weakly basic alkaloid present in several plant species [11] and shows antimicrobial activity against diverse pathogenic bacteria and fungi [12]. When an amino group or another electron-donating substituent is introduced at the 2-position of tryptanthrin, intramolecular charge transfer (ICT) occurs between the electron-withdrawing carbonyl group at its 6-position and the amino group resulting in strong fluorescence and positive fluorescence solvatochromism $[3 \mathrm{a}, 5,9]$. The fluorescence wavelengths of the fluorescent solvatochromic dyes vary according to the surrounding environment (polarity difference); therefore, a variety of life phenomena can be observed via the fluorescent color change. The fluorescent tryptanthrin derivatives have widespread potential applications in diverse fields such as labeling reagents, chemosensors, laser dyes, photosensitizers, and fluorescent organic devices. These dyes must be able to absorb and emit at long wavelengths for their various applications. We expect them to be of particular interest as organic fluorescent dyes for fluorescent imaging probes in biological research. The near-infrared (NIR) region $(650-900 \mathrm{~nm})$ is referred to as the "optical window" of cells and tissues because of the lack of efficient endogenous absorbers in this spectral range and the subsequent high penetration depth (of the order of a few millimeters) in most tissues [13]. Organic fluorescent dyes that emit NIR fluorescence are preferred for applications in biological systems because they can reduce auto-fluorescence and photodamage to living cells. Previously, 2-hydroxytryptanthrin (T2OH, Fig. 1b) was synthesized as a NIR dye for fluorescent imaging [6]. The absorption maxima $\left(\lambda_{\mathrm{a}, \max }\right)$ of $\mathbf{T 2 O H}$ in a $\mathrm{pH}$ range from 1.3 to 7.2 and from 8.5 to 10.6 were $c a .410 \mathrm{~nm}$ and $c a$. $495 \mathrm{~nm}$, respectively. Regardless of the $\mathrm{pH}$ range, the fluorescence maximum $\left(\lambda_{\mathrm{f}, \max }\right)$ was $c a .660 \mathrm{~nm}$. The $\lambda_{\mathrm{f}, \max }$ was in the optical window of $650 \mathrm{~nm}$ or more, but the $\lambda_{\mathrm{a}}$, max was $500 \mathrm{~nm}$ or less. Therefore, we planned to shift the $\lambda_{\mathrm{a}, \max }$ and $\lambda_{\mathrm{f}, \max }$ of $\mathbf{T 2 O H}$ to longer wavelengths by accelerating the ICT. We synthesized 2-hydroxytryptanthrin analog (2-(2-hydroxy-12-oxoindolo[2,1-b] quinazolin-6(12H)-ylidene)malononitrile, DCM-T2OH (Fig. 1c), in which the dicyanomethylene group was a better electron acceptor than the carbonyl group of $\mathbf{T 2 O H}$ as a NIR fluorescent dye for fluorescent imaging. In our study, we report on the spectral characteristics of DCM-T2OH.

a)

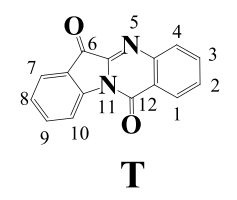

b)

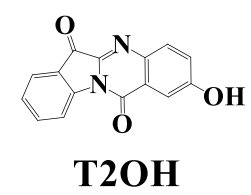

c)

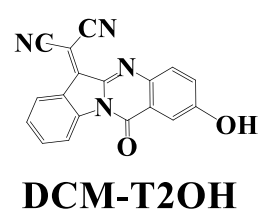

Fig. 1 Structural formulas of (a) T, (b) T2OH, and (c) DCM-T2OH.

\section{EXPERIMENTAL \\ 2.1 Synthesis}

The synthesis of DCM-T2OH was performed as follows (Scheme 1) [14]. T2OH [6] (0.1013 g, 0.3836 mmol) was dissolved in $5 \mathrm{ml}$ of dimethyl sulfoxide (DMSO) and malononitrile (0.1336 g, $2.022 \mathrm{mmol}$ ) was added into the solution. After adding two drops of concentrated hydrochloric acid, the mixture was stirred for $6 \mathrm{~h}$ at $90^{\circ} \mathrm{C}$ under an argon atmosphere. The reaction mixture was poured into ice/water, and the crude product was collected. Column chromatography on silica gel with 
ethyl acetate/dichloromethane $(1 / 4, \mathrm{v} / \mathrm{v})$ as the eluent yielded pure DCM-T2OH as a red solid $(0.0856 \mathrm{~g}$, $71.50 \%$ ). The electron-spray ionization (ESI) mass spectrum of DCM-T2OH showed the corresponding molecular ion peak, and the proton NMR spectrum showed that the compound was correctly synthesized.

DCM-T2OH: ${ }^{1} \mathrm{H}$ NMR $\left(500 \mathrm{MHz}, \mathrm{CDCl}_{3}\right) \delta 6.19(1 \mathrm{H}, \mathrm{s}$, $\mathrm{OH}), 7.34\left(1 \mathrm{H}, \mathrm{dd}, \mathrm{H}_{3}, J=3.0 \mathrm{~Hz}, J=8.6 \mathrm{~Hz}\right), 7.45(1 \mathrm{H}, \mathrm{t}$, $\left.\mathrm{H}_{8}, J=7.6 \mathrm{~Hz}, J=8.2 \mathrm{~Hz}\right), 7.76\left(1 \mathrm{H}, \mathrm{ddd}, \mathrm{H}_{9}, J=1.2 \mathrm{~Hz}\right.$, $J=7.6 \mathrm{~Hz}, J=8.4 \mathrm{~Hz}), 7.79\left(1 \mathrm{H}, \mathrm{d}, \mathrm{H}_{1}, J=3.0 \mathrm{~Hz}\right), 7.92$ $\left(1 \mathrm{H}, \mathrm{d}, \mathrm{H}_{4}, J=8.6 \mathrm{~Hz}\right), 8.47\left(1 \mathrm{H}, \mathrm{d}, \mathrm{H}_{7}, J=8.2 \mathrm{~Hz}\right), 8.60$ $\left(1 \mathrm{H}, \mathrm{d}, \mathrm{H}_{10}, J=8.4 \mathrm{~Hz}\right) ;$ ESI-MS $\mathrm{m} / \mathrm{z}(\mathrm{M}+\mathrm{H})$ calcd 313.0726, found 313.0591.

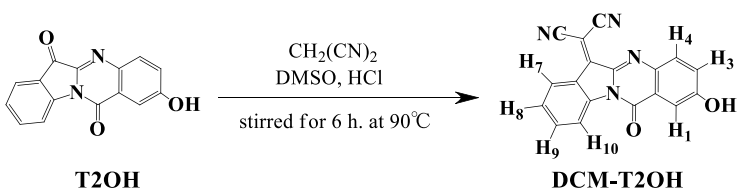

Scheme 1

\subsection{Measurements}

Stock solutions of DCM-T2OH were prepared by dissolving a weighed amount of each compound in different solvents. The ultraviolet and visible UV-vis spectra (between $300 \mathrm{~nm}$ and $900 \mathrm{~nm}$ ) of the resulting solutions were recorded at room temperature with a Jasco V-670 spectrophotometer. The fluorescence spectra were measured between $450 \mathrm{~nm}$ and $850 \mathrm{~nm}$ with a Hitachi F-4500 fluorometer using an excitation wavelength $\left(\lambda_{\text {ex }}\right)$ at the absorption band on the longest wavelength side. The concentration of all the samples was $10 \mu \mathrm{M}(\mathrm{M}=$ mol $\mathrm{dm}^{-3}$ ), and no intermolecular interactions were observed.

\section{RESULTS AND DISCUSSION}

3.1 Absorption and fluorescence spectra of DCM-T2OH

Absorption spectroscopy and fluorescence spectroscopy were performed using low-polarity aprotic solvents, high-polarity aprotic solvents, and protic solvents. The low-polarity aprotic solvents used were 1,4-dioxane (DOX, $2.10)$, toluene (PhMe, 2.43), chloroform ( $\mathrm{CF}, 4.89)$, and dichloromethane (DCM, 9.02). The numerical values in parentheses were the relative permittivities $(\varepsilon)$. The high-polarity aprotic solvents used were acetonitrile (MeCN, 36.00), dimethyl-formamide (DMF, 37.06), and dimethyl sulfoxide (DMSO, 47.00). The protic solvents used were ethanol (EtOH, 25.00) and methanol $(\mathrm{MeOH}$, 32.35). The absorption and fluorescence spectra of DCM-T2OH and the photophysical properties of DCM-T2OH are shown in Fig. 2, 3 and Table 1. In the low-polarity aprotic solvents, absorption bands of DCM-T2OH were observed at $c a .500 \mathrm{~nm}$, as shown in Fig 2a. These absorption bands are from undissociated DCM-T2OH. On the other hand, in the high-polar aprotic solvents, absorption bands were observed at $c a .700 \mathrm{~nm}$ as well as at ca. $500 \mathrm{~nm}$, as shown in Fig. 2b. These absorption bands on the long wavelength side are from ion-dissociated DCM-T2O-. In DMF and DMSO, which are more polar than $\mathrm{MeCN}$, the molar extinction coefficients of the absorption bands on the short wavelength side are smaller, and those of the absorption bands on the long wavelength side are larger. This result shows that there are more ion-dissociated DCM-T2O than undissociated DCM-T2OH in the solvents, which are more polar. In protic solvents, the absorption bands were observed at $c a .650 \mathrm{~nm}$ along with absorption bands at $c a$. $500 \mathrm{~nm}$, as shown in Fig. 2c. The absorption of ion-dissociated DCM-T2O ${ }^{-}$on the long wavelength side in the protic solvents was observed on the shorter wavelength side than in the high-polarity aprotic solvents because the ground state was stabilized by hydrogen bonding. In the low-polarity aprotic solvents, fluorescence bands of DCM-T2OH were observed at $c a .550 \mathrm{~nm}$, as shown in Fig 3. These fluorescence bands are from undissociated DCM-T2OH. However, in the high-polarity aprotic solvents and protic solvents, fluorescence bands of ion-dissociated DCM-T2O- ${ }^{-}$were observed at $c a .750 \mathrm{~nm}$ and $c a .770 \mathrm{~nm}$, as shown in Fig. 3. These results showed that in both high-polarity aprotic solvents and protic solvents, the ion-dissociated DCM-T2O ${ }^{-}$absorbs and fluoresces within the "optical window." In the aromatic

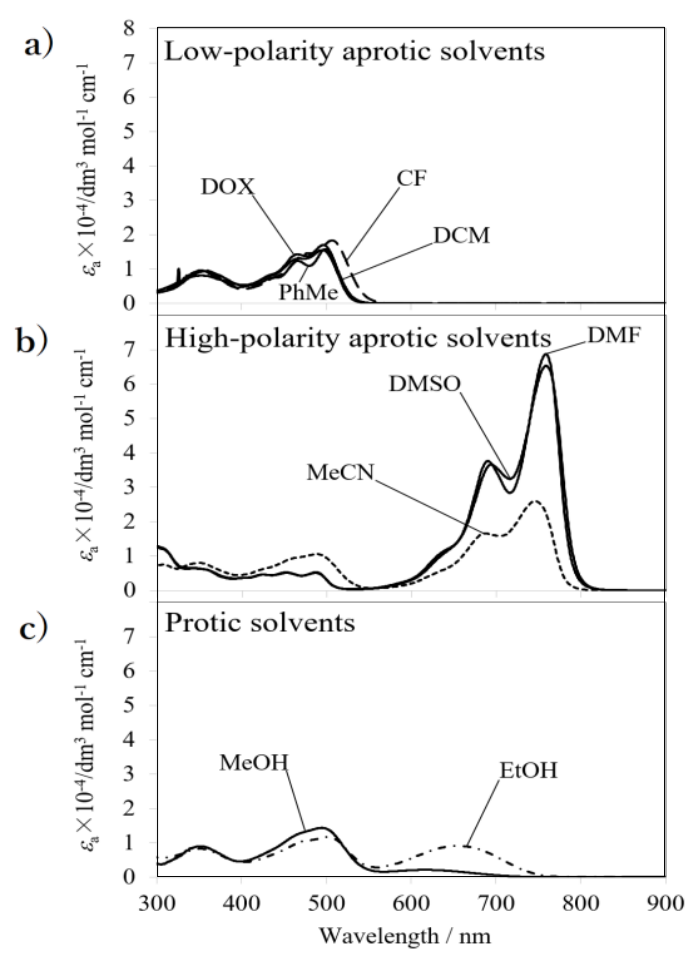

Fig. 2 UV-vis absorption spectra of DCM-T2OH in (a) low-polarity solvents, (b) high-polarity solvents, and (c) protic solvents.

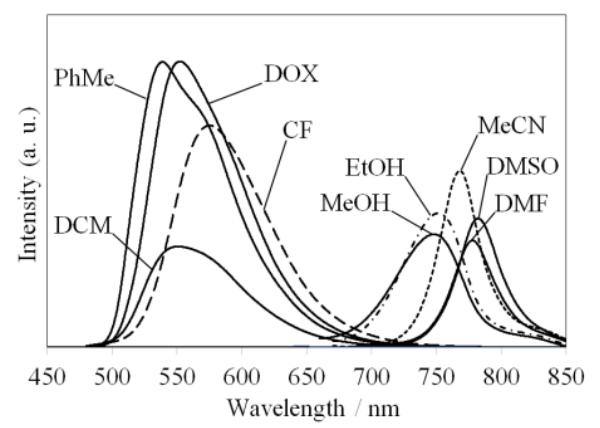

Fig. 3 Fluorescence spectra of DCM-T2OH in solvents with different polarities. 
Table 1. Absorption maxima ( $\left.\lambda_{\mathrm{a}, \max }\right)$, Molar absorbance coefficients $(\varepsilon)$, Emission maxima $\left(\lambda_{\mathrm{f}, \max }\right)$, Fluorescence quantum yields $\left(\Phi_{\mathrm{f}}\right)$, and Stokes shifts of DCM-T2OH.

\begin{tabular}{cccccc}
\hline Solvents & $\lambda_{\mathrm{a}, \max } / \mathrm{nm}$ & $\log \left(\varepsilon_{\mathrm{a}, \max } / \mathrm{dm}^{-3} \mathrm{~mol}^{-1} \mathrm{~cm}^{-1}\right)$ & $\lambda_{\mathrm{f}, \max } / \mathrm{nm}$ & $\Phi_{\mathrm{f}}^{\mathrm{b})}$ & Stokes shift $/ \mathrm{cm}^{-1}$ \\
\hline $\mathrm{DOX}$ & 497 & 4.23 & 552 & 0.08 & 2005 \\
$\mathrm{PhMe}$ & 499 & 4.20 & 539 & 0.08 & 1487 \\
$\mathrm{CF}$ & 507 & 4.26 & 575 & 0.10 & 2333 \\
$\mathrm{DCM}$ & 496 & 4.19 & 551 & 0.04 & 2012 \\
$\mathrm{MeCN}$ & $746^{\mathrm{a})}$ & 4.41 & $768^{\mathrm{a})}$ & 0.04 & 384 \\
$\mathrm{DMF}$ & $759^{\mathrm{a})}$ & 4.84 & $778^{\mathrm{a})}$ & 0.02 & 322 \\
$\mathrm{DMSO}$ & $759^{\mathrm{a}}$ & 4.82 & $782^{\mathrm{a}}$ & 0.02 & 388 \\
$\mathrm{EtOH}$ & $655^{\mathrm{a}}$ & 3.96 & 753 a) & 0.03 & 1987 \\
$\mathrm{MeOH}$ & $616^{\mathrm{a})}$ & 3.33 & $748^{\mathrm{a})}$ & 0.03 & 2865 \\
\hline
\end{tabular}

a. The value of ion-dissociated DCM-T2O-

b. The $\Phi_{\mathrm{f}}$ values were determined at room temperature relative to the absolute $\Phi_{\mathrm{f}}$ of 2 -( $N, N$-dimethylamino)tryptanthrin in dichloromethane $\left(\Phi_{\mathrm{f}}=0.89\right)[5]$ using solutions of matched absorbance $\left(0.1 \mathrm{~L} \mathrm{~mol}^{-1} \mathrm{~cm}^{-1}\right)$ at the excitation wavelength.

solvent toluene $(\mathrm{PhMe})$, a shoulder is observed around 570 $\mathrm{nm}$, as shown in Fig. 3. This shoulder could be due to intermolecular interactions such as exciplex formation between solvent and solute molecules.

\section{$3.2 \mathrm{pH}$ dependence of DCM-T2OH}

UV-vis absorption and fluorescence spectra of DCM-T2OH in a $\mathrm{MeCN} / \mathrm{H}_{2} \mathrm{O}(1 / 4$, v/v) solution containing 0.1 M HEPES at different $\mathrm{pH}$ are shown in Fig. 4. The $\mathrm{pH}$ was modulated by adding $0.1 \mathrm{M} \mathrm{HCl}$ or $0.1 \mathrm{M}$ $\mathrm{NaOH}$ in a MeCN/ $\mathrm{H}_{2} \mathrm{O}(1 / 4, \mathrm{v} / \mathrm{v})$ solution containing 0.1 $\mathrm{M}$ HEPES. At a $\mathrm{pH}$ of 7.1, the absorption of undissociated DCM-T2OH at $c a .500 \mathrm{~nm}$ and the absorption of ion-dissociated DCM-T2O- ${ }^{-}$at $c a .650 \mathrm{~nm}$ were observed. As the $\mathrm{pH}$ decreased, the absorption on the longer wavelength side disappeared (Fig. 4a-1). At a pH of 2.8 , only short wavelength absorption from undissociated DCM-T2OH was observed. In a $\mathrm{pH}$ range from 2.8 to 7.1, fluorescence bands were observed at $c a .750 \mathrm{~nm}$, as shown in Fig. 4b. This result occurs because of fluoresce by ion-dissociated chemical species, DCM-T2O- in the excited state as in the case of $\mathbf{T 2 O H}$ [6]. We expected that in an alkaline solution, the absorption at $c a .650 \mathrm{~nm}$ from ion-dissociated DCM-T2O $^{-}$would increase and the absorption at $c a .500 \mathrm{~nm}$ from undissociated DCM-T2OH would disappear. However, in a $\mathrm{pH}$ range from 7.1 to 11.5 , contrary to results expected, the absorption bands of ion-dissociated DCM-T2O ${ }^{-}$on the longer wavelength side disappeared as the $\mathrm{pH}$ increased (Fig. 4a-2). This result suggests that alkaline hydrolysis of DCM-T2OH to T2OH was suspected. Actually, the shape of the absorption spectrum at a $\mathrm{pH}$ of 11.5 was very similar to that of the proton-dissociated tryptanthrin-2-olate anion $\left(\mathbf{T 2 O}^{-}\right)$[6]. In a pH range from 8.0 to 11.5 , fluorescence spectra were observed at $c a .650 \mathrm{~nm}$, as shown in Fig. 4b. The shape of these fluorescence spectra was also very similar to that of $\mathbf{T 2 O}^{-}$. When acid was added to an alkaline solution of DCM-T2OH and neutralized and ESI-MS was measured, the $[\mathrm{M}+\mathrm{H}]^{+}$ion peak of $\mathbf{T 2 O H}$ was observed. This result confirmed that DCM-T2OH hydrolyzed to $\mathbf{T 2 O H}$ in the alkaline solution.

\section{CONCLUSION}

DCM-T2OH was synthesized as a NIR dye for fluorescent imaging. In high-polarity aprotic solvents (MeCN, DMF, and DMSO), protic solvents $(\mathrm{MeOH}$ and a-1)

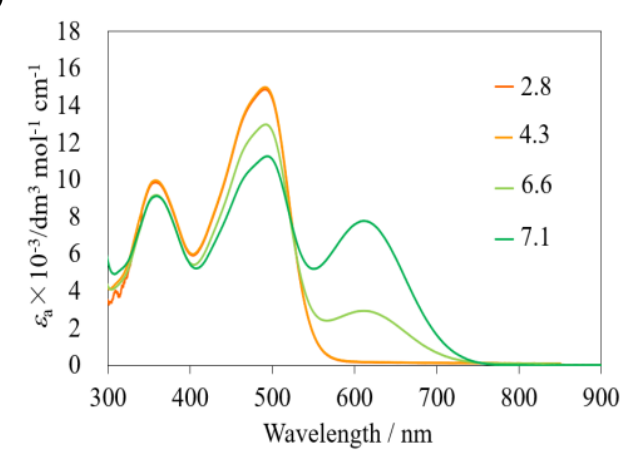

a-2)

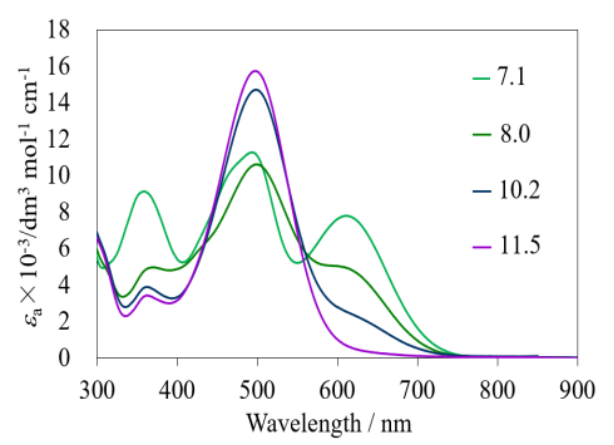

b)

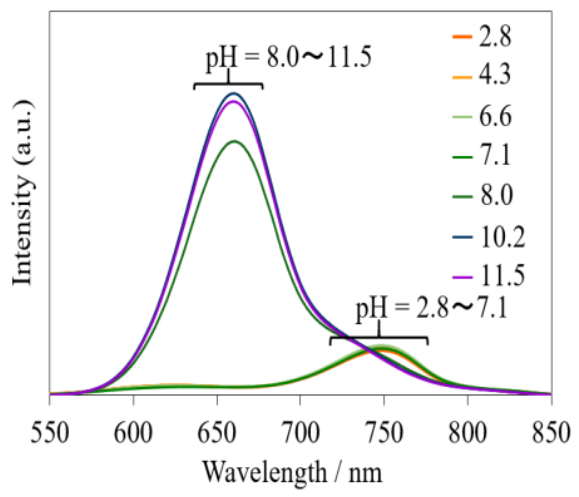

Fig. 4 (a) UV-vis absorption and (b) fluorescence spectra of DCM-T2OH in a $\mathrm{MeCN} / \mathrm{H}_{2} \mathrm{O}(1 / 4, \mathrm{v} / \mathrm{v})$ solution at different $\mathrm{pH}$ values. 
EtOH), and an aqueous solution containing $20 \%$ acetonitrile, both the absorption and fluorescence bands of DCM-T2OH were observed at the NIR region (650-900 $\mathrm{nm}$ ), which was referred to as the "optical window" of cells and tissues. In the acidic solution, ion-dissociated DCM-T2O $^{-}$regardless of $\mathrm{pH}$ fluoresced at $c a .750 \mathrm{~nm}$, while in the alkaline solution, ion-dissociated $\mathbf{T 2 O}^{-}$by hydrolysis of DCM-T2O- fluoresced at $c a .650 \mathrm{~nm}$.

\section{ACKNOWLEDGEMENTS}

This work was supported by JSPS KAKENHI Grant Number 16K05805 and 19K05518. The authors acknowledge Shared Facility Center for Science and Technology, Hirosaki University (SFCST) for Proton NMR and ESI mass spectrometry measurements. The authors would like to thank Enago (www.enago.jp) for the English language review.

\section{REFERENCES}

[1] H. Kobayashi, M. Ogawa, R. Alford, P. L. Choyke, and Y. Urano, Chem. Rev., 110, 2620-2640 (2010).

[2] H. Zhu, J. Fan, J. Du, and X. Peng, Acc. Chem. Res., 49, 2115-2126 (2016).

[3] a) J. Kawakami, H. Kawaguchi, K. Kikuchi, A. Yamaya, S. Ito, and H. Kitahara, Trans. Mat. Res. Soc. Japan, 38, 123-125 (2013); b) J. Kawakami, Tryptanthrin Derivatives, Patent No. 5448046, Japan (Jan. 10, 2014).

[4] a) J. Kawakami, A. Soma, K. Kikuchi, Y. Kikuchi, S. Ito, and H. Kitahara, Anal. Sci., 30, 949-954 (2014); b) J. Kawakami, K. Kikuchi, K. Chiba, N. Matsushima, A. Yamaya, S. Ito, M. Nagaki, and H. Kitahara, Anal. Sci., 25, 1385-1386 (2009).

[5] J. Kawakami, T. Kadowaki, M. Ikeda, Y. Habata, S. Ito, and H. Kitahara, Trans. Mat. Res. Soc. Japan, 41, 143-146 (2016).

[6] J. Kawakami, M. Takahashi, S. Ito, and H. Kitahara, Anal. Sci., 32, 251-253 (2016).

[7] J. Kawakami, Y. Kinami, M. Takahashi, and S. Ito, Trans. Mat. Res. Soc. Japan, 43, 109-112 (2018).

[8] J. Kawakami, M. Sasagawa, and S. Ito, Trans. Mat. Res. Soc. Japan, 43, 209-212 (2018).

[9] J. Kawakami, C. Osanai, and S. Ito, Trans. Mat. Res. Soc. Japan, 43, 319-323 (2018).

[10] J. Kawakami, M. Harada, and S. Ito, Trans. Mat. Res. Soc. Japan, 44, 153-156 (2019).

[11] A. Witt and J. Bergman, Curr. Org. Chem., 7, 659-677 (2003).

[12] L. A. Mitscher, W. C. Wong, T. De Meulenere, J. Sulko and S. Drake, Heterocycles, 15, 1017-1021 (1981).

[13] K. König, J. Microscopy, 200, 83-104 (2000).

[14] J. Bergman and U. Tilstam, Tetrahedron, 41, 2883-2884 (1985).

(Received September 30, 2019; Accepted January 15, 2020; Published Online February 1, 2020) 